\title{
O FENÔMENO DA DESCRIÇÃO NA ANÁLISE TEXTUAL DISCURSIVA: A DESCRIÇÃO FENOMENOLÓGICA COMO DESENCADEADORA DO METATEXTO
}

\author{
THE PHENOMENON OF DESCRIPTION IN DISCURSIVE TEXTUAL ANALYSIS: \\ THE PHENOMENOLOGICAL DESCRIPTION AS A METATEXT INITIATOR
}

\author{
MARIA DO CARMO GALIAZZI ${ }^{1}$ \\ ROBSON SIMPLICIO DE SOUSA²
}

\section{RESUMO}

Neste texto, temos como objetivo apresentar a "descrição" como desencadeadora da escrita no movimento analítico na Análise Textual Discursiva (ATD), metodologia qualitativa de análise difundida em pesquisas em Educação. Desconhecemos textos que abordem a temática descrição em ATD, o que também justifica elaborarmos compreensões acerca deste fenômeno. Temos nos dedicado a compreender a categoria na ATD. Para isso, fizemos um exercício de análise no livro "Análise Textual Discursiva" (MORAES e GALIAZZI, 2007), usando-a como metodologia de análise. A partir das influências teóricas desta metodologia, iniciamos pela pressuposição de que uma descrição densa permite uma imersão nos fenômenos estudados com implicações nas interpretações e significados atribuídos a eles em direção a sua compreensão. Entretanto, como argumento central, percebemos que, na ATD, a perspectiva fenomenológica orienta o processo de elaboração categorial, a produção do metatexto e exige a interpretação hermenêutica.

Palavras-chave: Análise Qualitativa. Descrição. Fenomenologia.

\section{ABSTRACT}

In this text, we aim to present the "description" as the initiator for writing in the analytical movement of the Discursive Textual Analysis (DTA), a qualitative methodology of analysis disseminated in Education research. It is not of our knowledge texts that approach the thematic of description in DTA, which also justifies to elaborate understandings about this phenomenon. We are dedicated to understand category in DTA. For this, we performed an analysis exercise in the book Discursive Textual Analysis (MORAES and GALIAZZI, 2007), using it as a methodology of analysis. From the theoretical influences of this methodology, we start with the assumption that a thick description allows us an immersion in the studied phenomena with implications to interpretations and meanings attributed to them towards their comprehension. However, as a central argument, we can perceive that in the DTA the phenomenological perspective guides the process of categorial elaboration, the production of the metatext and requires the hermeneutic interpretation.

Keywords: Qualitative Analysis. Description. Phenomenology.

\footnotetext{
1 Doutora em Educação. Professora Titular Aposentada na Universidade Federal do Rio Grande (FURG). Professora Voluntária no Programa de Pós-Graduação em Educação em Ciências: Química da Vida e Saúde da Universidade Federal do Rio Grande. E-mail: mcgaliazzi@gmail.com. Orcid: http://orcid.org/0000-0003-0513-0018

2 Doutor em Educação em Ciências. Professor Adjunto na Universidade Federal do Paraná (UFPR). Professor no Programa de Pós-Graduação em Educação em Ciências, Educação Matemática e Tecnologias Educativa (PPGECEMTE) da Universidade Federal do Paraná. E-mail: robson. simplicio@ufpr.br Orcid: http://orcid.org/0000-0002-4637-5014
} 


\section{INTRODUÇÃO}

A Análise Textual Discursiva tem sido uma metodologia de análise qualitativa difundida em investigações nos âmbitos da pesquisa em Educação (VALENTINE, SOARES E RELA, 2008; PIVETA e ISAIA, 2014; ROBAYO, 2015), Educação em Ciências (SOUSA e GALIAZZI, 2018) e outras áreas das humanidades. Esta difusão tem ocorrido desde a publicação do texto "Uma tempestade de luz: a compreensão possibilitada pela análise textual discursiva" (MORAES, 2003) que abre 0 livro inaugural de Análise Textual Discursiva (MORAES e GALIAZZI, 2007).

Entre influências teóricas da pesquisa qualitativa que deram origem à Análise Textual Discursiva estão a Análise de Conteúdo (BARDIN, 1977; MORAES, 1999, NAVARRO e DIAZ, 1995), a Pesquisa Naturalística (LINCOLN e GUBA, 1985), a fenomenologia (LUIJPEN, 1973; GILES, 1989) e a hermenêutica (GRONDIN, 1999). Essas influências nos levam a elaborar compreensões cada vez mais ampliadas acerca da ATD em diferentes trabalhos. Em nossos estudos especificamente sobre características da categorização da Análise Textual Discursiva (SOUSA e GALIAZZI, 2017; GALIAZZI e SOUSA, 2019) temos percebido a categoria como modo de lidar com o material empírico que exige do pesquisador uma ampliação deste lidar em direção a um modo mais perceptivo e intuitivo em múltiplos movimentos dialéticos.

0 presente artigo apresenta mais uma categoria emergente deste estudo em torno da categoria/ categorização da ATD. Da análise, o que se mostrou como um fenômeno a ser teorizado é a "descrição" na ATD, temática ainda pouco abordada em trabalhos que envolvem esta metodologia de análise. Assim, em nosso caminho analítico, primeiro unitarizamos todo o livro de Análise Textual Discursiva (MORAES e GALIAZZI, 2007) com o uso do software Atlas.ti, buscando compreender o que se mostra na ATD de categoria e desta categorização surgiram subcategorias.

Neste texto, estamos apresentamos o trabalho de análise da subcategoria "descrição". As Unidades de Significado (US) aparecem na ordem em que foram produzidos os diferentes capítulos que compõem o livro, o que mostrou, como apontaremos no texto, diferentes significados atribuídos à descrição ao longo da obra. Ao todo foram cinquenta e sete (57) unidades de significado em que a descrição e o descrever se mostram. 0 Código que identifica a unidade, por exemplo, 6:101, significa que é 0 sexto documento primário colocado no software Atlas.ti para 0 estudo, neste caso, 0 livro de ATD. 0 número que segue 0 seis é o número da unidade de significado identificada. Apresentamos somente as US que mais nos informam sobre o que é descrever ou a descrição, pois em muitas das unidades de significado não há detalhamento algum, apenas a palavra que designa um dos momentos iniciais da escrita sempre com descrição e interpretação aparecendo juntas no livro, constituindo o processo em seu todo no movimento de teorização.

Primeiramente, apresentamos uma síntese dos procedimentos da ATD com o objetivo de esclarecer ao leitor, mesmo que brevemente, esta metodologia de análise de informações textuais. A seguir fazemos dois movimentos analíticos: do conceito à palavra, movimento descendente quando pretendemos entender mais os significados daquela palavra em um texto e um segundo movimento analítico, o movimento da palavra ao conceito, quando buscamos significados atribuídos historicamente e teoricamente àquela palavra, aproximando-nos, assim, em uma fusão de horizontes, da compreensão do conceito com ampliação da compreensão do texto (GADAMER, 2000; ROHDEN, 2012). Neste movimento ascendente, contemplamos um dos movimentos, o de relacionar imagens $e$ usos com a palavra, reproduzindo parte de uma descrição efetuada pelos autores da ATD no próprio livro analisado. 


\section{UMA SÍNTESE DA ANÁLISE TEXTUAL DISCURSIVA}

A Análise Textual Discursiva, metodologia de pesquisa qualitativa com cunho fenomenológico-hermenêutico, é uma metodologia que estabelece a partir do corpus uma estrutura de categorias em que inicia pela descrição do fenômeno. Este primeiro movimento de descrever é sucedido por processos interpretativos pelos quais se busca ampliar os sentidos do fenômeno em análise de modo a compreendê-lo melhor. As categorias constituem os elementos de organização do metatexto. É a partir delas que se produzirão as descrições e interpretações que irão compor o texto como expressão de novas compreensões advindas da análise (MORAES e GALIAZZI, 2007).

A Análise Textual Discursiva é descrita como um processo que se inicia com uma unitarização em que os textos são separados em unidades de sentido para o pesquisador $e$ transformados em unidades de significado. Estas unidades por si mesmas podem gerar outros conjuntos de unidades oriundas da interlocução empírica, da interlocução teórica e das interpretações feitas pelo pesquisador. Neste movimento de interpretação do significado expresso no texto, exercita-se a apropriação das palavras pronunciadas por outras vozes para compreender melhor 0 texto. Depois da realização desta unitarização, que precisa ser feita com intensidade e profundidade, passa-se a fazer a articulação de significados semelhantes em um processo denominado de categorização. Neste processo reúnem-se as unidades de significado semelhantes, podendo gerar vários níveis de categorias de análise.

Há dois movimentos de elaboração de categorias com a ATD: as categorias a priori, construções dedutivas em que o pesquisador elabora as categorias a partir de teorias de fundamentação do trabalho antes mesmo de realizar a análise, e as categorias emergentes, construções teóricas indutivas e intuitivas elaboradas a partir do corpus de análise (MORAES e GALIAZZI, 2007). Entre estes dois movimentos, existe um movimento misto de categorização, que parte de categorias a priori e as complementa ou as reorganiza na análise (SOUSA e GALIAZZI, 2017; 2018).

Ao se considerar a amplitude das categorias na ATD, pode-se estruturar categorias com maior ou menor amplitude. Na categorização a priori, elas são estruturadas, normalmente, do geral ao específico, enquanto na emergente, do específico ao mais amplo, mas ambas conduzem à produção de um conjunto de categorias que vai dar origem ao metatexto com descrições e interpretações dos materiais analisados (SOUSA e GALIAZZI, 2017).

A categoria na ATD está dentro desta dialética do a priori e do emergente, seja em termos de produção categórica, seja em termos de teorização para a produção do metatexto em passos posteriores de análise (GALIAZZI e SOUSA, 2019). Quando o pesquisador conhece de antemão os temas em análise, separa as unidades de acordo com esses temas ou em suas categorias a priori, dentro dos propósitos da pesquisa. Trata-se da categorização com natureza mais objetiva e dedutiva que se diferencia de uma categorização indutiva e mais subjetiva produzida por categorias emergentes, uma construção gradativa do objeto de pesquisa. Nas categorias a priori, a teoria apresenta seus exemplares empíricos. Na categorização emergente, a categorização constitui um elemento central para se chegar à teorização. Quando presta atenção à intuição como uma componente estruturante das categorias em que a semelhança de unidades pode provocar organizações a análise ganha cunho mais fenomenológico (SOUSA e GALIAZZI, 2017).

Há uma estreita relação entre categorização e a teorização de uma análise, em que o nível de teorização atingido é um indicador de sua qualidade. Com categorias a priori, o pesquisador deriva suas categorias de seus pressupostos teóricos e, portanto, elas já estão definidas antes da análise e classificação das unidades. Este processo exige um profundo conhecimento da teoria assumida a 
priori e, a partir disso, é de mais fácil condução. 0 pesquisador descreve 0 que aprendeu nas teorias assumidas antes da análise e as categorias serão descrições advindas daquele aporte teórico. Nas categorias emergentes, o pesquisador assume deixar que os fenômenos se manifestem a partir das múltiplas vozes dos textos que analisa. Este é um processo que exige conviver com a insegurança de um caminho a ser construído (MORAES, 2002). Neste processo da ATD, há possibilidade maior de criatividade do pesquisador em relação às categorizações a priori.

Em teorias definidas e assumidas a priori, as categorias são como "repositórios" nos quais as informações são colocadas e organizadas. Na ATD, em qualquer dos modos, busca-se que o pesquisador torne as teorias mais complexas e ampliadas. Independente do movimento de elaboração de categorias - a priori ou emergente - a partir da explicitação de sistema de categorias, o pesquisador as descreve para chegar a produzir argumentos (SOUSA e GALIAZZI, 2017). Em qualquer dos processos de categorização a partir delas é que se concretiza o movimento inicial de escrita pela descrição das unidades de significado, como mostraremos a seguir.

\section{INICIAÇÃO DESCRITIVA DA CATEGORIA}

Instituições, coisas, ambiente e objetos assim como pessoas e personagens são passíveis de descrição, no entanto, muitas vezes em um texto, quando aparece uma descrição, não é dada a ela muita atenção (GUEDES, 2009). No entanto, se esta é uma atitude de um leitor distraído, é importante na pesquisa que usa a descrição na análise, a ela se atentar. Esta foi a intencionalidade fenomenológica nesta parte do texto, que é deixar que a descrição se mostre em um movimento que parte dos significados que se mostram no texto. Este movimento descendente é de escuta e compreensão para que 0 outro se manifeste, deixar o outro se manifestar (ROHDEN, 2012).

A descrição se mostra no livro de Análise Textual Discursiva (MORAES e GALIAZZI, 2007) como movimento primeiro de escrita em que descrever as categorias e subcategorias é apresentar as informações empíricas. Isso já está no primeiro capítulo do livro Uma Tempestade de Luz: a compreensão possibilitada pela Análise Textual Discursiva:

A descrição na análise textual qualitativa concretiza-se a partir das categorias construídas ao longo da análise. Descrever é apresentar as categorias e subcategorias, fundamentando e validando essas descrições a partir de interlocuções empíricas ou ancoragem dos argumentos em informações retiradas dos textos. Uma descrição

densa, recheada de citações dos textos analisados, sempre selecionadas com critério e perspicácia, é capaz de dar aos leitores uma imagem fiel dos fenômenos que descreve. Essa é uma das formas de sua validação. (6:39, grifo nosso)

Esta unidade de significado aponta para um sistema de análise categorial em que as informações empíricas fundamentam e validam a pesquisa. A descrição densa da obra, é um termo contextualmente apropriado na ATD do paradigma naturalístico de pesquisa (LINCOLN e GUBA, 1985). Chama atenção neste fragmento a importância de estar mostrando pela descrição uma imagem fiel do fenômeno, o que se aproxima mais de um entendimento de descrição objetiva da realidade.

0 exercício de escrita em que a ATD aposta em obter compreensões ampliadas tem como resultado os metatextos, que foram definidos por Navarro e Diaz (1995) na Análise de Conteúdo (AC). Nos dois termos, estrutura e metatexto que são constitutivos da descrição, percebemos a aproximação 
de uma análise categorial como a proposta na $A C$ e que se mostra novamente no terceiro capítulo do livro Análise Textual Discursiva (MORAES e GALIAZZI, 2007) intitulado Construindo Quebra-cabeças ou Produzindo Mosaicos? Aprendizagem e comunicação no processo de categorização:

A análise textual discursiva pode ser caracterizada como exercício de produção de metatextos, a partir de um conjunto de textos. Nesse processo constroem-se estruturas de categorias, que ao serem transformadas em textos, encaminham descrições e interpretações capazes de apresentarem novos modos de compreender os fenômenos investigados. (6:101, grifo nosso)

A organização das categorias fora apresentada em texto anterior de Moraes (1999) sobre a AC, que, de acordo com Bardin (2009), é um conjunto de instrumentos metodológicos, é uma hermenêutica controlada baseada na dedução: a inferência, oscilando entre o rigor da objetividade e a fecundidade da subjetividade.

A escrita na ATD, assim como a própria organização das categorias, é aperfeiçoada em processos recursivos de leitura e de reescrita. Isto aufere à escrita maior coerência, consistência e amplia a compreensão do pesquisador sobre o tema, como está colocado no capítulo quatro, Movimentando-se entre as Faces de Jano: 0 Comunicar e o Aprender na Produção Escrita que Acompanham a Análise Textual Discursiva:

Em qualquer das formas de análise, a qualidade de um texto depende de sua estrutura ou macro-organização. Esta pode ser organizada a partir do conjunto de categorias e subcategorias construídas ao longo do processo de análise (Moraes, 1999). A estrutura de categorias encaminha descrições, interpretações e novas argumentações, representando, em seu conjunto a teorização e compreensão construídas a partir da pesquisa. Saber utilizar as categorias construídas na análise para organizar a produção escrita é um modo de atingir descrições e interpretações válidas dos fenômenos investigados. Tal como as próprias categorias, a estrutura do metatexto necessita ser aperfeiçoada ao longo do processo da escrita, atingindo-se modos de organização cada vez mais coerentes e consistentes, juntamente com a compreensão construída em relação ao fenômeno investigado. (6:108, grifo nosso)

É 0 movimento de descrição que vai levar as interpretações e as organizações em direção à compreensão e, para isso, a descrição que pretende ser válida precisa ser densa, intensamente empírica e carregada de detalhes. Descrever é expressar de modo organizado, então, pelas categorias os sentidos e significados que se mostram nos textos de análise e, para isso, é necessário que a descrição tenha ancoragem na realidade empírica, nas unidades de significado,

Para que uma produção escrita seja válida, tanto em seus aspectos descritivos como interpretativos, os sujeitos da pesquisa precisam se sentir contemplados em seus modos de compreender os fenômenos investigados. Assim, os textos produzidos precisam expressar mais do que a compreensão pessoal do pesquisador. Precisam descrever explicações e compreensões dos participantes, ainda que reconstruídas pelo pesquisador. Isso, evidentemente, não precisa ser atingido num sentido pessoal de cada participante, mas num sentido discursivo coletivo, numa base sociocultural, segundo expressão de Marques. (6:111, grifo nosso) 
Neste fragmento, percebemos uma aproximação com o paradigma naturalístico que trouxe para as pesquisas em Ciências Sociais e para a Educação esta interpretação de que é possível alcançar a compreensão dos participantes, o que é questionado pela hermenêutica filosófica (GADAMER, 2000). 0 que se alcança é compreender, sempre finitamente, os sentidos do texto. A referência a Marques (1997) se justifica em função da importância atribuída ao escrever à medida que 0 autor a articula à escrita e ao pesquisar. Assim,

[...] pesquisar é produzir um texto de rica intertextualidade no qual se conjuguem, em uma intersubjetividade sempre ativa e provocante desde suas bases socioculturais, as muitas vozes de uma comunidade argumentativa especialmente convocada para 0 debate em torno de determinada temática; sejam as experiências do pesquisador, sejam os testemunhos de um campo empírico, sejam os testemunhos do respectivo campo teórico. (MARQUES, 1997, p. 229)

Não está em foco em Marques (1997), entretanto, alcançar a compreensão do participante, mas produzir um texto em que as vozes dos participantes da pesquisa, sejam interlocutores empíricos ou teóricos, estejam presentes, como se mostra em outra Unidade de Significado no texto:

\begin{abstract}
Afirmar que as produções escritas originadas de uma pesquisa precisam ser válidas, é dizer que necessitam ter capacidade descritiva, o que é garantido a partir da validade das categorias e dos argumentos construídos. Essa validade diz respeito à pertinência do que se afirma em relação aos fenômenos investigados e, uma das formas de consegui-la, é o uso de depoimentos, falas ou expressões escritas dos sujeitos participantes das pesquisas. É o que se denomina ancoragem empírica (Bernardo, 2000). Para que uma produção escrita seja válida, tanto em seus aspectos descritivos como interpretativos, os sujeitos da pesquisa precisam se sentir contemplados em seus modos de compreender os fenômenos investigados. (6:111, grifo nosso)
\end{abstract}

0 metatexto que inicia descritivo, pela ATD, incorpora diferentes diálogos com as informações empíricas e teóricas com a intenção de chegar à argumentação. Cada categoria se organiza por algum critério de semelhança em que é importante o cuidado na descrição, pois é a partir dela que vão se atingir níveis mais complexos de interpretação e, com isso, também o pesquisador se mostra. Ainda que as descrições constituam parte da pesquisa, elas estão próximas do empírico e da realidade investigada, conferindo menos autoria ao pesquisador. A descrição sozinha pouco contribui para alcançar a compreensão. Segundo a ATD:

Um bom texto vai da descrição e narrativa para a interpretação e argumentação. Segundo Demo (2001) a extensão se descreve; a profundidade solicita argumentos. Os argumentos vão além das descrições e das categorias. (6:116, grifo nosso)

Uma das finalidades de produzir um sistema de categorias é a produção do metatexto a partir dos textos do corpus. Trata-se de um metatexto descritivo e interpretativo que vai ao final expressar novas compreensões do pesquisador sobre o fenômeno. A descrição é o primeiro movimento recursivo de escrita na garantia de alcançar estas novas compreensões e, até mesmo, interferir nos discursos sobre o fenômeno. 
Em outro capítulo intitulado MERGULHOS DISCURSIVOS: análise textual discursiva entendida como processo integrado de aprender, comunicar e interferir em discursos, um dos últimos que compõem a obra, é retomada a importância da descrição densa e dos metatextos encaminhando-se a análise para uma teorização, mesmo que a descrição possa representar uma teorização ainda frágil a ser ampliada com exercícios posteriores de análise e escrita:

Ainda que seguidamente possam ser trabalhadas de modo integrado, em geral, a primeira etapa da produção do metatexto é a descrição. A categorização encaminha a descrição do objeto de estudo. Descrever é apresentar diferentes elementos que emergem dos textos analisados e representados pelas diferentes categorias construídas. "Descrever é produzir proposições ou enunciados que enumerem qualidades, propriedades, características, etc., do objeto ou fenômeno que se descreve" (JORBA, 2000, p. 43). Segundo o mesmo autor a descrição deve ser pertinente, completa e precisa, ainda que seja importante entender essas características como algo desejado, mas nunca inteiramente atingido. A descrição visa a apresentar elementos importantes do objeto de pesquisa. Para isso utiliza-se das categorias e subcategorias da análise, tendendo a permanecer num nível concreto dos fenômenos, ou seja, numa aproximação com a realidade empírica. É importante superar descrições superficiais, procurando-se atingir descrições densas dos fenômenos investigados. A descrição, de algum modo, já é uma interpretação. (6:135, grifo nosso)

Neste fragmento também nos parece que a descrição está mais próxima da realidade objetiva, quantificável completa e precisa embora aponte também que isso nunca possa ser inteiramente alcançado. A descrição, no entanto, não se basta como movimento analítico. Em relação à questão da teorização nas pesquisas e, mais especificamente na ATD, os autores enfatizam que as descrições, as interpretações e a teorização que se atingem no processo indicam a qualidade da pesquisa e com isso é preciso superar meras descrições.

No capítulo intitulado Análise Textual Discursiva: Análise de Conteúdo? Análise de Discurso?, apresentam-se unidades de significado do texto que procuram diferenciar a ATD em relação a AC e a Análise do Discurso (AD). No entanto, mostra-se uma compreensão distanciada da realidade objetiva: "Nenhum discurso pode ser descrito de modo integral. os resultados de qualquer análise sempre apresentam apenas uma versão parcial e incompleta dos fenômenos investigados." (6:222). É neste texto de diferenciação da $A C$ e da $A D$, colocando-se como uma metodologia diferente, que fica marcada a aproximação com a Fenomenologia quando no texto está escrito que:

Preferimos introduzir em nossa discussão o termo descritivo, com base no trabalho de Joel Martins (1984), em que 0 autor, discutindo pesquisas fenomenológicas, enfatiza os níveis descritivos e interpretativos como formas de se apresentar os resultados de análise, formas de explicitar-se uma nova compreensão de um fenômeno. (6:226)

É também neste mesmo texto que fica situada a ATD em processos fenomenológicos e hermenêuticos:

0 processo da Análise Textual Discursiva tem fundamentos na Fenomenologia e na Hermenêutica. Valoriza os sujeitos em seus modos de expressão dos fenômenos. 
Centra sua procura em redes coletivas de significado construídos subjetivamente e que o pesquisador se desafia a compreender, descrever e interpretar. São processos hermenêuticos. (6:227)

0 modo como a descrição é apresentada transita entre um viés mais objetivo de proximidade com o empírico que pretende trazer 0 que os participantes quiseram dizer, o que eles perceberam ou ainda 0 que compreenderam. Considerando a ordem de elaboração dos textos de ATD, pareceu-nos que os primeiros estão mais próximos de procedimentos oriundos na Análise de Conteúdo. À medida que se avança na leitura do livro, mostra-se a influência do paradigma naturalístico e da Fenomenologia. Os textos finais, Metamorfoses Múltiplas: emergências incertas e inseguras no caminho da Análise Textual discursiva, Um Contínuo Ressurgir de Fênix: reconstruções discursivas compartilhadas na produção escrita e Avalanches Reconstrutivas: movimentos dialéticos e hermenêuticos de transformação no envolvimento com a Análise Textual Discursiva - este último publicado em Moraes e Galiazzi (2016) -, como síntese de todo o processo, não atentam para a descrição e, de acordo com 0 argumento que atingimos compreender, foi um movimento em direção à hermenêutica produzido a partir de fusões descritivas e interpretativas apontados nos textos anteriores.

Este foi o movimento analítico descendente, em que se buscou expressar os significados atribuídos à descrição no livro Análise Textual Discursiva (MORAES e GALIAZZI, 2007) como um todo. Vamos a seguir apresentar o estudo da descrição em direção a fusão de horizontes no movimento ascendente de análise, como 0 apresenta Rohden (2012) considerando a dialética nestes dois movimentos à luz da hermenêutica, como apontamos em Galiazzi e Sousa (2019).

\section{A DESCRIÇÃO EM DIREÇÃO À FUSÃO DE HORIZONTES}

Buscando avançar na compreensão do conceito e, com isso, alcançar a ampliação de sentidos sobre a descrição na ATD, apresentamos o movimento da palavra ao conceito, movimento ascendente de compreensão. Exploraremos o movimento ascendente em seus cinco momentos interligados: nome, definição, imagem, o conhecimento em direção ao quinto momento, a coisa mesma (ROHDEN, 2012).

0 primeiro momento de análise conforme o movimento ascendente é o nome enunciado, neste caso, descrição. A partir dos significados atribuídos ao nome e seus assemelhados na linguagem, como descrever e descrito, que sentidos são atribuídos à palavra descrição? A definição, segundo movimento ascendente, é composta de nomes e verbos e, partindo inicialmente do nome, vamos em direção à definição nos dicionários de uso comum da língua portuguesa. Segundo Houaiss (2009), descrição é 0 ato de descrever. Descrever é representar-se por escrito ou oralmente. É uma reprodução, um traçado, uma delimitação, uma reprodução de algo de modo oral ou escrito. Descrever é fazer um relato circunstanciado de algum acontecimento, de um fato, de um objeto. É contar em detalhes. É também narrar. Descrever também se usa quando se quer riscar, desenhar, traçar um objeto e ainda quando se quer traçar o percurso de um processo.

Se estes são os significados registrados na linguagem comum, ainda no momento da definição, em dicionários de Filosofia como Abbagnano (2018), seguimos em direção ao conceito. A descrição é 0 discurso que conduz pelas marcas à coisa. Conduz à singularidade da coisa que a distingue das outras, focando, então, no objeto mais do que quem descreve. A descrição se diferencia da definição, pois enquanto a definição é universal a descrição é singular, o que distingue a coisa de outra. Nos dois significados, no entanto, parece-nos que a descrição torna possível alcançar a coisa, embora 
esteja dito que é pelas marcas do discurso que se chega à coisa, mas não necessariamente ao que ela é (GADAMER, 2000; ROHDEN, 2012). Considerando o terceiro movimento, a imagem, em que se criam exemplos e usos à descrição, apresentamos um exemplo do uso da descrição na ATD.

\section{UMA DESCRIÇÃO EXEMPLAR}

0 sétimo capítulo do livro de ATD intitulado Metamorfoses múltiplas: emergências incertas e inseguras no caminhar da Análise Textual Discursiva é resultado de uma pesquisa realizada com mestres e doutores que realizaram a análise das informações produzidas em suas pesquisas por meio da ATD. Foram realizadas doze (12) entrevistas. Trazemos no Quadro 1 parte de uma possível descrição das Unidades de Significado retiradas das entrevistas com a intenção de contemplar 0 terceiro momento analítico, a imagem, do movimento da palavra ao conceito. As Unidades de Significado foram reunidas em uma categoria denominada de $A$ metamorfose do sujeito-autor.

Quadro 1 - Apresentação das unidades de significado identificadas na entrevista do capítulo "Metamorfoses múltiplas: emergências incertas e inseguras no caminhar da Análise Textual Discursiva" e suas respectivas descrições.

\begin{tabular}{|l|l|}
\hline \multicolumn{1}{|c|}{ Unidade de significado na entrevista } & \multicolumn{1}{c|}{ Unidade de significado descrita } \\
\hline $\begin{array}{l}\text { "Voltei a ouvir as entrevistas gravadas para } \\
\text { ver se havia coerência entre os recortes e as } \\
\text { falas". (Ma101) }\end{array}$ & $\begin{array}{l}\text { A mestranda afirma que voltou a ouvir as entrevistas para ver se havia coerência entre os } \\
\text { recortes e as falas. Expressa a preocupação de na unitarização manter a coerência com 0 } \\
\text { sentido do todo da entrevista. (Ma101) }\end{array}$ \\
\hline $\begin{array}{l}\text { "Sei que ainda não está bom, pois está muito } \\
\text { disperso e solto. Mas vou enviar para as orien- } \\
\text { tadoras para não continuar o trabalho sobre o } \\
\text { que pode ser um erro novamente". (Ma102) }\end{array}$ & $\begin{array}{l}\text { A mestranda sabe que o trabalho ainda não está bom, pois está disperso e solto. Pretende } \\
\text { encaminhar para as orientadoras a fim de evitar erros que já ocorreram anteriormente. A } \\
\text { mestranda tem confiança em suas orientadoras que irão lhe apontar se está no caminho } \\
\text { certo. Tem como certo alcançar um nível de articulação e coesão no texto. (Ma102) }\end{array}$ \\
\hline $\begin{array}{l}\text { "Acho que está bom, mas falta uma revisão } \\
\text { para ver alguns problemas, que nem sei quais } \\
\text { são direito, pois se soubesse já iria tentar } \\
\text { resolvê-los". (Mo1.01) }\end{array}$ & $\begin{array}{l}\text { 0 mestrando considera que a análise esteja boa, embora perceba que a análise apresen- } \\
\text { ta problemas e não os saiba identificar. Se os soubesse, tentaria resolvê-Ios. Expressa } \\
\text { intenção de melhorar o trabalho, embora tenha dúvidas de como consegui-lo. 0 papel do } \\
\text { orientador, neste sentido, de acompanhar indicando possibilidades é fundamental (M01.01). }\end{array}$ \\
\hline $\begin{array}{l}\text { "Todo o processo foi de extremo trabalho, } \\
\text { muita leitura e escrita". (Me1.01) }\end{array}$ & $\begin{array}{l}\text { Ao rever a análise desenvolvida, a mestre afirma que o processo da ATD foi trabalhoso com } \\
\text { muita escrita e leitura. (Me1.01) }\end{array}$ \\
\hline $\begin{array}{l}\text { "Nunca escrevi tanto em tão pouco tempo". } \\
\text { (Me1.02) }\end{array}$ & Isso exigiu da mestranda que escrevesse muito em pouco tempo. (Me1.02) \\
\hline $\begin{array}{l}\text { “Mesmo sendo um processo trabalhoso, o fim } \\
\text { justifica e compensa os meios”. (Me1.03) }\end{array}$ & $\begin{array}{l}\text { Afirma que embora seja um processo trabalhoso, os resultados compensam as dificulda- } \\
\text { des durante a análise. (Me1.03) }\end{array}$ \\
\hline
\end{tabular}

Fonte: Construção dos autores a partir de Moraes e Galiazzi (2007).

No exemplo, estabelecemos um código - codificação - para identificar se a Unidade de Significado foi produzida a partir da fala de um mestre (Me), mestranda (Ma) ou mestrando (Mo). 0 código permite retornar ao texto de onde a unidade foi retirada, se for necessário.

0 quarto movimento ascendente da palavra em direção ao conceito é o da ciência, o do conhecimento. A descrição constitui procedimento em diferentes metodologias e abordagens nas pesquisas qualitativas (PONTEROTTO, 2006; BARDIN, 2009; BICUDO, 2011). Em sua elaboração, a ATD teve a influência da Análise de Conteúdo, do Paradigma Naturalístico, da Fenomenologia e da Hermenêutica e a estas perspectivas nos ativemos para compreender a descrição. 
Para Navarro e Diaz (1995), teóricos da AC referenciados na obra analisada, a descrição é 0 movimento de primeira escrita do metatexto. 0 metatexto, que é a escrita do pesquisador pode ter elementos textuais de diferentes tipos. Pode conter gráficos, é produto do pesquisador. É resultado de uma articulação dupla do sentido do texto e do processo interpretativo que o esclarece:

0 metatexto resultante na AC consiste em uma transformação do corpus operada por regras definidas e que devem ser teoricamente justificadas pelo pesquisador através de uma interpretação adequada. Desde este ponto de vista, a AC deve entender-se como um conjunto de mecanismos capazes de produzir perguntas, e não como uma receita para obter respostas. (NAVARRO e DIAZ, 1995, p. 182)

Em consonância com Bardin (2009), os autores citados apresentam os procedimentos que seguem na AC próximos da quantificação numérica de presenças de palavras, sentenças, expressões. Moraes (1999), que antes de apresentar a ATD, teorizou sobre a AC, aborda nela a descrição a partir da categorização como esforço de comunicação dos resultados de uma pesquisa. Se a pesquisa foi realizada em uma abordagem quantitativa, a organização da descrição será em tabelas e gráficos. No entanto, em uma abordagem qualitativa a descrição será de outra ordem:

Para cada uma das categorias será produzido um texto síntese em que se expresse 0 conjunto de significados presentes nas diversas unidades de análise incluídas em cada uma delas. Geralmente é recomendável que se faça uso intensivo de "citações diretas" dos dados originais. Este ainda não será o momento interpretativo, ainda que poderá haver descrições cada vez mais abrangentes, dependendo dos níveis de categorização. De um modo geral a organização desta descrição será determinada pelo sistema de categorias construído ao longo da análise. 0 momento da descrição é, sem dúvida, de extrema importância na análise de conteúdo. É o momento de expressar os significados captados e intuídos nas mensagens analisadas. Não adianta investir muito tempo e esforço na constituição de um conjunto de categorias significativo e válido, se no momento de apresentar os resultados não se tiver os mesmos cuidados. (MORAES, 1999, p. 8, grifo nosso).

Como grifamos no excerto acima, a descrição na AC que inicia a apresentação das categorias, como cita Moraes (1999), é o momento de expressar significados captados e intuídos das informações contidas no texto.

A descrição densa também se constitui em imagem e uso da palavra. Para Lincoln e Guba (1985) a descrição densa é um modo de ter validade externa fornecendo detalhes que permitem avaliar a validade das conclusões. 0 termo foi inicialmente usado por Ryle (1949) e depois aplicado por Geertz (1973) na etnografia. Para Geertz, a descrição densa se refere a um conjunto detalhado de informaç̧ões das experiências empíricas nas quais o pesquisador explicita os padrões das relações culturais e sociais e as contextualiza (HOLLOWAY, 1997; PONTEROTTO, 2006).

Para Oliveira (2013), Geertz ao propô-la parte da tradição hermenêutica, ainda que se reconheça que nunca é possível saber o sentido expresso por um sujeito, ou se tratando de interpretar culturas, a interpretação nunca é de "primeira mão". Mas como propõe Geertz, a pretensão em descrever é alargar o universo do discurso humano (TALAMONI, 2016). 
É importante, pois, que na descrição densa, o pesquisador mostre que mergulhou no fenômeno, que esteve lá. É claro que esta descrição tem graus de subjetividade dos quais não há como escapar. Querer evitá-la é estar mais próximo de paradigmas com cunho na objetividade, a considerar que possa se alcançar uma realidade. Mesmo que a escrita seja densa e atenta ao fenômeno observado, 0 autor está presente na descrição pelo modo como se manifesta, como constrói 0 texto, o vocabulário usado. No entanto, a amplitude ou minúcia da descrição não é o que garante à apreensão de uma realidade. A complexidade do fenômeno só pode ser alcançada quando se aprofunda tanto a descrição quanto a interpretação. Mesmo assim, nunca é possível recompor a imediatez do trabalho empírico. 0 pesquisador sempre percebe algumas coisas e ignora outras (GEERTZ, 1973). Na descrição densa é preciso estabelecer uma comunicação tanto com os interlocutores empíricos quanto com os futuros leitores do texto. 0 que está sendo descrito é um exemplo que vai levar, juntamente com o conjunto de descrições, a compreender o fenômeno.

Ponterotto (2006) integrando o trabalho de vários dos precursores que teorizaram a descrição densa afirma que os componentes de uma descrição densa são: 1. a descrição e a interpretação de forma acurada de ações sociais dentro de um contexto apropriado no qual a ação social acontece; 2. a descrição densa captura pensamento, emoções e a rede de interação social entre participantes observados em seu contexto operativo; 3 . uma característica central para a interpretação social engloba motivações e intenções para as ações em análise; 4 . 0 contexto e as especificidades da ação social precisam estar tão bem descritos que o leitor experimenta um senso de verossimilhança ao ler o que está sendo descrito. Para Denzin (1989), a verossimilhança refere-se a "afirmações verdadeiras que produzem nos leitores a sensação de que eles experimentaram ou poderiam experimentar os eventos que estão sendo descritos" (p. 83-84); 5. descrição densa das ações sociais promove "interpretação densa" dessas ações, que levam ao "significado denso" das descobertas que ressoam com os leitores (PONTEROTTO e GRIEGER, 2007). Para Ponterotto (2006), a descrição, a interpretação e o significado podem ser melhor entendidos pela metáfora de uma árvore para explicar a interligação destes três conceitos. A "descrição detalhada" constitui as raízes da árvore que nutrem e alimentam a "interpretação densa", representada pelo tronco sólido da árvore, que por sua vez alimenta os galhos e folhas da árvore, que representam o "significado denso". São os galhos e folhas que mais capturam a atenção dos observadores, como é o caso do "significado denso", cujo resultado chama mais a atenção aos leitores de um relatório de pesquisa.

Descrição densa refere-se à tarefa do pesquisador de descrever uma ação social observada dentro de seu contexto particular. 0 contexto pode estar dentro de uma unidade menor (como uma sala de aula, um projeto, um ambiente de trabalho) ou unidade (como um curso, uma escola, uma comunidade). Para Ponterotto (2006) a descrição densa descreve com precisão as ações sociais observadas e atribui propósito e intencionalidade a essas ações, por meio do entendimento do pesquisador e da descrição clara do contexto em que as ações sociais ocorreram. A descrição densa capta os pensamentos e sentimentos dos participantes, bem como a rede muitas vezes complexa de relacionamentos entre eles.

A descrição densa tem nela mesma a influência da Fenomenologia de Husserl. Ao criticar a semelhança dos métodos das ciências Naturais para a Filosofia, Husserl funda sua filosofia na compreensão de que a existência humana está engajada no mundo da vida e daí resulta toda a experiência. Outro aspecto da Fenomenologia que guarda relação com a descrição densa de Geertz é a intencionalidade com que o pesquisador observa um fenômeno. A partir destas duas influências. Segundo Talamoni (2013), o que também influenciou Geertz (1973) em sua abordagem da descrição densa foi 
a fenomenologia de Merleau-Ponty, pois coloca importância na percepção e na subjetividade distanciando-se então de uma intenção mais de objetividade.

"A descrição é básica na Fenomenologia, uma vez expressado e comunicado, o percebido já não é do sujeito, mas está apresentado (dado) à comunidade, solicitando, então, procedimentos de análise e interpretação" (BICUDO, 2011, p. 19). A descrição relata a experiência vivida. Os modos de expressar essas experiências vividas podem ser de expressão direta ou podem expor as experiências em textos do pesquisador que expressam discursos inteligíveis. No primeiro caso, temos uma descrição imediata e no segundo uma descrição intermediada (idem, p. 45).

Não há a garantia de que a descrição seja exata com o que descreve. Em uma abordagem fenomenológica, pode haver tantas descrições quantas forem os sujeitos que descrevem um fenômeno. No entanto, é preciso que reproduza como é que o fenômeno se mostra a quem o descreve.

0 mérito principal de uma descrição não é sempre a sua exatidão ou seus pormenores, mas a capacidade que ela possa ter de criar uma reprodução tão clara possível para o leitor da descrição. Poderá haver tantas descrições de uma mesma coisa quantas sejam as pessoas especialistas que vejam essa mesma coisa. (MARTINS, 1991, p.56)

Neste sentido, não há o modo de descrever correto e 0 errado, o que é verdadeiro ou a descrição que seja falsa:

É possível inferir que não existem descrições certas e descrições erradas, mas, antes, descrições boas ou más, mais completas ou menos completas. Não há lugar para o verdadeiro em oposição ao falso em uma descrição, pois toda descrição se dá de forma afirmativa, parte de uma positividade. (MARTINS, 1991, p. 57)

A descrição vai dizer do que foi percebido por aquele que descreve. Não julga e mesmo que toda descrição possa ser uma interpretação, busca não interpretar. Da descrição é que se encaminham a análise e a interpretação. A Fenomenologia que se atém ao relato do percebido, do sentido pelo sujeito que descreve para a interpretação busca aportes da Hermenêutica (BICUD0, 2011).

Apresentamos aqui os quatro momentos analíticos do movimento ascendente em direção ao conceito: nome, definição, imagem e conhecimento. Estes movimentos articulados tramam as condições para a compreensão da coisa, a descrição de algo, entretanto, não é este algo que se quer descrever. 0 quinto movimento é o conhecimento que o sujeito alcança sobre este algo descrito, que é diferente de todos os outros movimentos e deles não prescinde, mas também deles se diferencia (ROHDEN, 2012), que é a compreensão finita que alcançamos, neste caso, da descrição na categoria, como também é finita a compreensão de quem por ventura venha ler este texto.

\section{CONCLUSÃO}

$\mathrm{Na}$ articulação dos dois movimentos analíticos descendente e ascendente, a intenção deste texto foi de compreender a descrição na ATD que se mostra como exercício inicial de escrita das categorias. As categorias estruturam o fenômeno em análise e o metatexto, texto resultante da descrição e, posterior, interpretação. A descrição se mostra nos metatextos na presença de informações dos interlocutores empíricos da pesquisa e se diferencia das proposições de descrição apresentada 
pela AC que se estabelece mais por informações quantitativas, inferências, frequências e estatísticas. Não se atém a todos os quesitos exigidos em uma descrição densa. Insere-se na descrição fenomenológica com os interlocutores empíricos muito presentes no metatexto em um movimento de escuta, a deixar que o fenômeno se mostre. A descrição, embora importante em uma análise, não se basta. Ela exige movimento de interpretação para ampliar a compreensão.

Pretendemos mostrar que este texto é resultado de pesquisa fenomenológica-hermenêutica, chamando atenção que, pelo exercício analítico com ATD, o movimento descendente de análise, que requer o movimento ascendente aqui mostrado em relação à descrição, nesta articulação, produz o metatexto.

\section{REFERÊNCIAS}

BARDIN, L. Análise de Conteúdo. 1. ed. Lisboa: Edições 70, 1977.

Análise de Conteúdo. 6. ed. Lisboa: Edições 70, 2009.

BICUDO, M. A. V. Pesquisa Qualitativa segundo a visão fenomenológica. 1. ed. São Paulo: Cortez, 2011.

DENZIN, N. Interpretive interactionism. Newbury Park, CA: Sage, 1989.

GADAMER, H.-G. Da palavra ao conceito: a tarefa hermenêutica enquanto filosofia. In: ALMEIDA, L. S.; FLICKINGER, H.-G.; ROHDEN, L. Hermenêutica Filosófica. Porto Alegre: EDIPUCRS, 2000. p. 13-26

GALIAZZI, M. do C.; SOUSA, R. S. de. A dialética na categorização da análise textual discursiva: o movimento recursivo entre palavra e conceito. Revista Pesquisa Qualitativa, São Paulo,v.7, n. 13, p. 01-22, abr. 2019.

GEERTZ, C. The Interpretation of Cultures. New York: Basic Books, 1973.

GILES, T. R. História do existencialismo e da fenomenologia. São Paulo: Editora Pedagógica e Universitária, 1989.

GRONDIN, J. Introdução à hermenêutica filosófica. São Leopoldo: Editora da Unisinos, 1999.

HOLLOWAY, I. Basic Concepts for Qualitative Research. London: Blackwell Science, 1997.

LINCOLN, Y. S.; GUBA, E. G. Naturalistic Inquiry. Newbury Park, CA: Sage Publications, 1985.

LUIJPEN, W. Introdução à fenomenologia existencial. São Paulo: Editora Pedagógica e Universitária, 1973.

MARQUES, M. O. Escrever é preciso. ljuí: Editora Unijuí, 1997.

MARTINS, J. A pesquisa qualitativa. In: FAZENDA, I. (Org.). Metodologia da pesquisa educacional. 2 ed. São Paulo: Cortez, 1991. p. 48-58.

MORAES, R. Análise de conteúdo. Educação (PUCRS), Porto Alegre (RS), v. 22, n. 37, p. 7-32, 1999. 
. No ponto final a clareza do ponto de interrogação inicial: a construção do objeto de uma pesquisa qualitativa. Educação (PUCRS), Porto Alegre (RS), v. 25, n. 46, p. 231-248, 2002.

Uma tempestade de luz: a compreensão possibilitada pela análise textual discursiva. Ciência \& Educação, Bauru (SP), v. 9, n. 2, p. 191-211, 2003.

MORAES, R.; GALIAZZI, M. C. Análise Textual Discursiva: processo reconstrutivo de múltiplas faces. Ciência \& Educação, Bauru (SP), v. 12, n. 1, p. 117-128, 2006.

. Análise Textual Discursiva. 1. ed. Ijuí: Editora Unijuí, 2007.

. Análise textual discursiva. 3. ed. Rev. e Ampl. ljuí: Editora Unijuí, 2016.

NAVARRO, P.; DÍAZ, C. Análisis de Contenido. In: DELGADO, J. M.; GUTIÉRREZ, J. (Org.): Métodos y técnicas cualitativas de investigación en ciencias sociales, Madrid: Síntesis, 1995. p.177-224

OLIVEIRA, A. Etnografia e pesquisa educacional: por uma descrição densa da educação. Educação Unisinos, São Leopoldo (RS), v. 17, n. 3, p. 271-280, set./dez. 2013.

PIVETTA, H. M. F.; ISAIA, S. M. de A. Movimientos constructivos de un grupo de profesores reflexivos. Rev. Port. de Educação, Braga (PT), v. 27, n. 1, p. 111-132, jun. 2014.

PONTEROTTO, J. G. Brief note on the origins, evolutions, and meaning of the qualitative research concept "thick description". The Qualitative Report, Fort Lauderdale (FL), v. 11, n. 3, p. 538-549, 2006.

PONTEROTTO, J. G.; GRIEGER, I. Effectively communicating qualitative research. The Counseling Psychologist, v. 35, n. 3, p. 404-430, 2007.

ROBAYO, A. R. P. A análise textual discursiva na investigação educativa. Educação, Ciência e Cultura, Canoas (RS), v. 20, n. 2, p. 129-149, 2015.

ROHDEN, L. Filosofando com Gadamer e Platão. Dissertatio, Pelotas (RS), v. 36, p. 105-135, 2012.

RYLE, G. The Concept of Mind. London: Hutchinson, 1949.

SOUSA, R. S. de; GALIAZZI, M. do C. A Categoria na Análise Textual Discursiva: Sobre Método e Sistema em Direção à Abertura Interpretativa. Revista Pesquisa Qualitativa, São Paulo,v. 5,n. 9,p. 514-538, dez. 2017.

. 0 jogo da compreensão na análise textual discursiva em pesquisas na educação em ciências: revisitando quebra-cabeças e mosaicos. Ciência \& Educação, Bauru, v. 24, n. 3, p. 799-814, jul./set. 2018.

TALAMONI, A. C. B. Possíveis contribuições metodológicas da Antropologia Interpretativa de Clifford Geertz às pesquisas em Ensino de Ciências. Atas do IX Encontro Nacional de Pesquisa em Educação em Ciências - IX ENPEC Águas de Lindóia, SP - 10 a 14 de nov. 2013. 
Os nervos e os ossos do ofício: uma análise etnológica da aula de Anatomia [online]. São Paulo: Editora UNESP, 2014.

VALENTINI, C. B.; SOARES, E. S.; RELA, E. Formação de professores do ensino superior: o desafio de repensar o fazer pedagógico no contexto das tecnologias e da modalidade semipresencial. Educação Unisinos, São Leopoldo (RS), v. 12, n. 3, p. 196-204, 2008.

RECEBIDO EM: 03 nov. 2020

CONCLUÍDO EM: 23 mar. 2021 
